\title{
Endotherapy in Pancreatic Diseases
}

\author{
Vaneet Jearth ${ }^{1}$ Surinder S. Rana ${ }^{1}$ \\ ${ }^{1}$ Department of Gastroenterology, Postgraduate Institute of Medical \\ Education and Research (PGIMER), Chandigarh, India \\ J Digest Endosc 2022;13:19-29.
}

\begin{abstract}
Address for correspondence Surinder S. Rana, MD, DM, FASGE, FSGEI, Department of Gastroenterology, Postgraduate Institute of Medical Education and Research (PGIMER), Chandigarh 160012, India (e-mail: drsurinderrana@gmail.com).
\end{abstract}

\begin{abstract} Keywords

- pancreatitis

- endosonography

- endoscopic retrograde cholangiopancreatography

- stent

Interventional endoscopy is now considered an effective minimally invasive treatment modality for the management of pancreatic diseases. It is important for the clinician to know the indications and contraindications as well as the timing of various endoscopic interventions. This will help in its safe and effective use and consequently decrease morbidity and mortality from various pancreatic diseases. This review will provide a broad overview of the indications, techniques, and outcomes of pancreatic endotherapy.
\end{abstract}

\section{Background}

Interventional endoscopy is now considered an effective minimally invasive treatment modality in the management of pancreatic diseases. This review will focus on the role of endotherapy in the management of acute pancreatitis and its complications, recurrent acute pancreatitis, chronic pancreatitis, pancreatic cancer, pancreatic neuroendocrine tumors, and cystic lesions of the pancreas.

\section{Endotherapy in Acute Pancreatitis}

The role of endotherapy when a patient initially presents with acute pancreatitis (AP) is mainly limited to two situations: first, patients with acute biliary pancreatitis (ABP) and, second, to place nasojejunal/nasogastric tube for nutritional support.

\section{Acute Biliary Pancreatitis}

The role and timing of Endoscopic retrograde cholangiopancreatography (ERCP) in ABP is still a topic of debate in absence of cholangitis. ${ }^{1}$ ERCP in patients with ABP is usually performed in patients with cholangitis ( $<24$ hours) or prolonged cholestasis (i.e., an elevated serum bilirubin level that fails to fall suggesting persistent biliary obstruction). The recently completed ABP: urgent ERCP with sphincterotomy versus Conservative treatment (APEC) trial randomized 230 patients with predicted severe ABP and the results of this study support a conservative strategy in patients with predicted severe ABP without cholangitis or persistent cholestasis. ${ }^{2}$ EUS can help to confirm common bile duct stones before ERCP in absence of obvious signs of biliary obstruction and prevent unnecessary ERCP and consequent adverse events. ${ }^{1}$

\section{Enteral Feeding}

Early enteral feeding (preferably within 24-72 hours) for patients with severe acute pancreatitis is recommended in view of a significant reduction in infectious complications, mortality, and organ failure rates. ${ }^{3}$ Nasogastric (NG) feeding appears to be as effective as nasojejunal (NJ) feeding. ${ }^{3} \mathrm{~A}$ randomized controlled study has also suggested that $\mathrm{NJ}$ fluid resuscitation with oral rehydration solution is feasible and is equally efficacious in patients with acute pancreatitis as intravenous fluid resuscitation with ringer lactate. ${ }^{4} \mathrm{NJ}$ resuscitation also resulted in the early institution of enteral feeding. NJ feeding has also been shown to improve pain in
DOI https://doi.org/ 10.1055/s-0041-1741423. ISSN 0976-5042.
(C) 2022. Society of Gastrointestinal Endoscopy of India. All rights reserved.

This is an open access article published by Thieme under the terms of the Creative Commons Attribution-NonDerivative-NonCommercial-License, permitting copying and reproduction so long as the original work is given appropriate credit. Contents may not be used for commercial purposes, or adapted, remixed, transformed or built upon. (https://creativecommons.org/ licenses/by-nc-nd/4.0/)

Thieme Medical and Scientific Publishers Pvt. Ltd., A-12, 2nd Floor, Sector 2, Noida-201301 UP, India 
patients with pancreatic fluid collections and thus obviate or delay drainage. ${ }^{5}$

\section{Endotherapy in Local Complications of Acute Pancreatitis}

There are a variety of local complications that can arise as a consequence of AP with defined nomenclature. ${ }^{6}$ Based on the revised Atlanta classification, these include peri-pancreatic fluid collections (PFC), pancreatic and peripancreatic necrosis (sterile or infected), and pseudocyst and walled-off necrosis (WON; sterile or infected). Acute peri-pancreatic collections form early in the course of AP and usually resolve without any intervention. Intervention should be delayed as long as possible depending upon the clinical status of the patient to allow time ( $>4$ weeks) for encapsulation of collection (pseudocyst or WON). ${ }^{7}$

Endotherapy now provides an effective minimally invasive treatment modality for complications of AP with an approach to their management simplified in three steps: delay, drain and if necessary, debride. ${ }^{8}$ Percutaneous drainage (PCD) can be utilized as a temporizing measure for source control in critically ill and septic patients prior to PFC maturation. Although there is recent data on the safety and efficacy of endoscopic transmural drainage in patients with partially enclosed PFC, PCD currently is used in the majority of patients with symptomatic pancreatic fluid collections without a well-defined wall. ${ }^{9-11}$ Early endoscopic interventions might be performed in patients with partial or complete encapsulated PFC, but careful consideration should be given to endoscopic drainage in the very early stage $(<2$ weeks) due to limited safety data and absence of encapsulation.

The following section will focus on the role of endotherapy in the management of local complications, recognizing that PCD itself may be adequate in $23-55 \%$ of patients with infected or symptomatic necrotizing pancreatitis avoiding step up endoscopic or surgical therapy. ${ }^{12}$

\section{Pseudocysts}

Acute pseudocysts usually arise as a sequela of AP, require at least 4 weeks to encapsulate, and are devoid of significant solid debris. In some patients with significant early acute pancreatic necrosis ( $>30 \%$ necrosis), the peripancreatic and pancreatic necrosis may evolve into a collection that on computed tomography resembles a pseudocyst. ${ }^{13}$ Also, over a period of time the solid necrotic content in WON may liquefy and the collection may resemble an acute pseudocyst. ${ }^{14,15}$ Drainage of an acute pseudocyst is indicated if the patient is symptomatic or the pseudocyst is infected. Pseudocysts may be drained by trans papillary or transmural (through gastric/duodenal wall) route. $^{16}$

\section{Transpapillary Drainage}

Transpapillary drainage alone with or without sphincterotomy can be attempted for smaller pseudocysts (less than $6 \mathrm{~cm}$ ) when there is a communication of pseudocyst with the main pancreatic duct (PD). ${ }^{17}$ Evidence from two studies does not support the use of combined transpapillary and transmural drainage in the management of pseudocyst as opposed to the transmural approach alone. ${ }^{18,19}$ Yang et al ${ }^{19}$ demonstrated that pancreatic duct stenting along with transmural drainage for pancreatic pseudocyst negatively affects the long-term resolution of PFC's. However, PD disruption was not characterized as partial or complete in this multicenter trial and only $36.2 \%$ of patients received bridging stents. ${ }^{20}$ Transpapillary drainage alone of larger pseudocysts should be avoided as it is associated with increased risk of infection because of the limited ability of narrow caliber transpapillary stents to drain large PFC's. In this setting, use of nasopancreatic drain is preferred, as it is associated with lower risk of infection as compared with use of stent. ${ }^{21}$ Any downstream stricture can lead to persistence of pseudocyst so bridging the duct disruption or stricture is considered the preferred approach because it restores ductal continuity and appears to be more effective. ${ }^{22} 5$ to $8.5 \mathrm{Fr}$ size plastic stents can be used as per pancreatic duct diameter on pancreatogram and are usually left in place for 4-6 weeks.

\section{Transmural Drainage}

The transmural drainage involves the creation of a conduit between the gut and the collection (cystogastrostomy or cystoduodenostomy). It is performed by entering the collection using a needle without electrocautery or using an electrocautery device (e.g., needle knife, cystotome, cautery-enhanced lumen apposing metal stent [LAMS]. ${ }^{23}$ EUS is now the preferred modality for transluminal drainage, as it enables accurate visualization and puncture of PFC independent of the presence of endoscopically visible bulge, and the use of color Doppler during EUS avoids injury to intervening blood vessels. Two RCTs have shown improved outcomes with EUS guided approach as compared with blind endoscopic drainage. ${ }^{24,25}$ EUS guided drainage with LAMS is preferred for drainage of larger PFC as well as collections with significant solid debris because their larger luminal diameter facilitates prompt drainage and longer patency of the stent. ${ }^{26}$ However, their use in pseudocysts does not appear to be advantageous over plastic stents probably given the absence of solid debris resulting in effective drainage via plastic stents also. Therefore plastic stents may be preferred over LAMS in the management of patients with pancreatic pseudocysts as their use seems to be cost-effective. ${ }^{27}$ Till date no randomized studies have addressed the optimal number of plastic stents that should be inserted for adequate drainage of an acute pseudocyst. It appears that placement of two plastic stents (7-10 F) may provide optimal drainage of an acute pseudocyst. ${ }^{28}$

While many studies do not differentiate between PFCs in describing treatment outcomes, a recent review reported a clinical success rate of $94 \%$ with endoscopic drainage of pseudocysts. ${ }^{29}$ A cross-sectional imaging prior to drainage is recommended to delineate the detailed anatomy as well as to detect any vascular complication that may preclude transluminal drainage. ${ }^{28}$ 


\section{Walled Off Necrosis}

The landmark PANTER trial provided evidence about the superiority of minimally invasive step-up approach, where a percutaneous drain is initially inserted followed by a step up to endoscopic and/or minimally invasive surgery was compared with open surgical necrosectomy in patients of infected necrosis or WON. ${ }^{30}$ Refractory abdominal pain, gastric outlet obstruction, or failure to thrive (i.e., continued systemic illness, anorexia, and weight loss) at 4 or more weeks after the onset of acute pancreatitis are indications for drainage of sterile WON. Three recent RCTs have reported better outcomes with an endoscopic approach in infected necrotizing pancreatitis. ${ }^{31-33}$ However, the difference in the treatment approaches with regards to the type of stents used and variable use of co-interventions (e.g., percutaneous drainage and number of debridement procedures performed), might add heterogeneity to the results of these trials.

Current strategies for managing WON include placement of large diameter LAMS or Bi-flanged Metal Stents (BFMS) to provide efficient drainage of solid necrotic debris and facilitate direct endoscopic necrosectomy (DEN), if necessary (-Fig. 1). Three designs of metal stents are available, BFMS (Nagi, Taewoong, South Korea), LAMS (Spaxus, Taewoong, South Korea, and Axios, Boston Scientific, United States), and lumen apposing stents with cautery enhanced tip (Hot Spaxusand Hot Axios Boston Scientific). A multicenter study showed that in comparison to plastic stents, LAMS in WON is associated with higher clinical success, shorter procedure time, lower rate of recurrence, and lower need for surgery. ${ }^{34}$ Studies from our center showed similar technical success, rates of WON resolution, and complications in patients treated with multiple plastic stents and LAMS. However, LAMS were associated with a significantly shorter time to

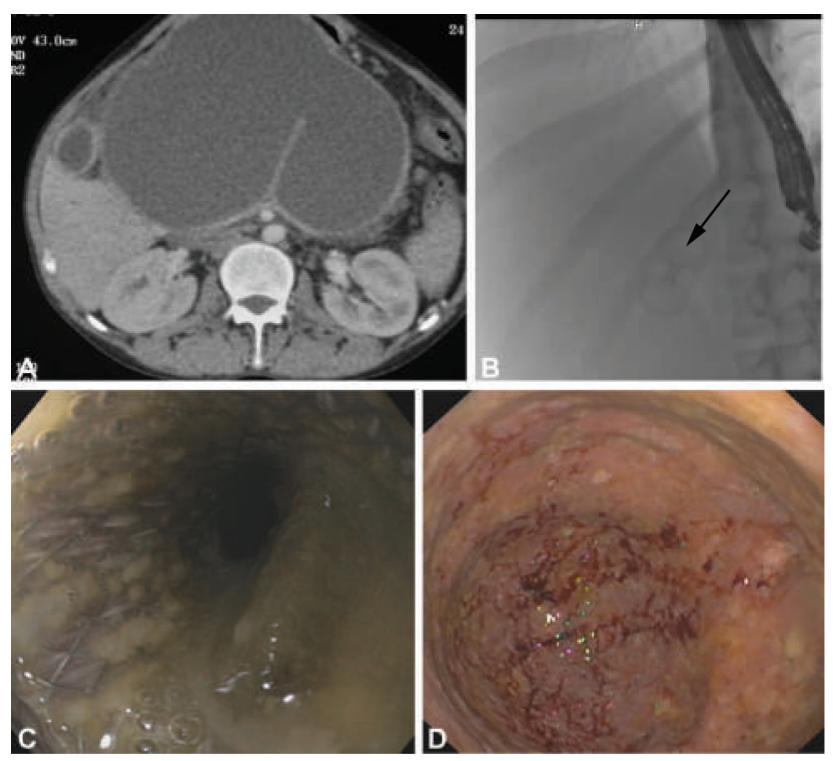

Fig. 1 (A) CT abdomen: Large WON. (B) EUS-guided drainage: a lumen apposing metal stent (Hot Axios) deployed. (C) Direct endoscopic necrosectomy (DEN): endoscope being negotiated into the WON cavity through the stent. (D) Post DEN: resolved WON with healthy granulation tissue in the cavity. resolution. ${ }^{35}$ In RCT of 60 patients, Bang et al showed higher stent-related adverse events (bleeding, biliary stricture) with the use of LAMS than with double pigtail plastic stents with similar clinical success. ${ }^{36}$ Therefore removal of LAMS is advised at 3-4 weeks after insertion with insertion of plastic stents in exchange in case of partial resolution of WON. DEN is not routinely performed and is reserved for those patients who fail to improve or demonstrate clinical deterioration in view of associated complications ranging from 3 to $35 \%$ (bleeding, air embolism, perforation), and 6-8\% mortality. ${ }^{8,37}$ The addition of a coaxial double pigtail stent inside a LAMS/BFMS may be associated with lower rates of SEMS migration. ${ }^{28}$ The role of transpapillary drainage in patients with acute necrotizing pancreatitis is unclear and a recent review suggested that transpapillary pancreatic duct stenting could improve the results of endoscopic transmural drainage of WON. ${ }^{38}$

\section{Disconnected Duct Syndrome}

Disconnected duct syndrome (DDS) is a complication of necrotizing pancreatitis affecting $\sim 30-50 \%$ of patients. ${ }^{8}$ The leak of pancreatic juice from the remnant pancreas leads to recurrent PFC or refractory external pancreatic fistulae (EPF) and ductal hypertension in the disconnected segment results in recurrent abdominal pain/pancreatitis. Due to complete disruption in DDS, transpapillary drainage is usually considered to be ineffective as bridging with a pancreatic stent is often not feasible. ${ }^{39}$ In the current endoscopic era, management of DDS has shifted from open surgery to minimally invasive endotherapy, though DDS is still more likely to require hybrid therapy, re-intervention, rescue surgery, and often results in a longer hospital stay. ${ }^{40}$ Fluid collections with DDS are drained transmurally with plastic stents left in place indefinitely whereas external pancreatic fistulae with DDS usually require surgery or complex EUS guided interventions. ${ }^{8,41}$

\section{Endotherapy in Recurrent Acute Pancreatitis}

Recurrent acute pancreatitis (RAP) is defined as 2 or more episodes of acute pancreatitis with complete resolution of symptoms between episodes in patients with no evidence of chronic pancreatitis. ${ }^{42}$ Recurrence occurs in $11-32 \%$ of patients with acute pancreatitis resulting in RAP. ${ }^{43}$ Preventing recurrences is important because repeated episodes of AP can lead to chronic pancreatitis in almost one-third of patients. ${ }^{42}$ Here, we will focus on the causes of RAP that can be treated endoscopically or endoscopy plays an important role in their management.

\section{Biliary Etiology}

\section{Gall Stones}

Indications of ERCP in gall stone-related pancreatitis have been discussed previously. EUS plays a very important role in the selection of patients for ERCP in cases of ABP that are at intermediate risk (abnormal LFTs and/or CBD dilation on Ultrasound) for persistent choledocholithiasis. ${ }^{44}$ 


\section{Microlithiasis}

Microlithiasis are gallstones $<3 \mathrm{~mm}$ in size and cannot be visualized on abdominal ultrasound. EUS offers the best modality to diagnose microliths with a sensitivity of $96 \%{ }^{43}$ Laparoscopic cholecystectomy is an intervention of choice in these patients to prevent further episodes of AP. Endoscopic biliary sphincterotomy can be done if pancreatitis recurs after surgery and in those unfit for cholecystectomy. ${ }^{45}$

\section{Tumors}

Pancreatobiliary tumors are considered to be a less common but important cause of RAP and should be considered as a cause of AP in patients older than 50 years with no identifiable etiology. EUS is the most sensitive modality for diagnosing small peri-ampullary tumors, intraductal papillary mucinous neoplasm, and pancreatic tumors $<2 \mathrm{~cm}$ in size and should be part of the diagnostic algorithm for evaluation of idiopathic AP in the elderly. ${ }^{43}$ EUS also permits obtaining cytological samples by fine-needle aspiration/biopsy. EUS plays an important role in staging ampullary lesions to determine the feasibility of endoscopic resection.

\section{Choledochocele}

A choledochocele is a cystic dilatation of the intraduodenal portion of the common bile duct which can present with RAP likely as a result of bile reflux into the pancreas. EUS can aid in accurate diagnosis and endoscopic sphincterotomy forms the current standard of treatment by unroofing the cyst and separating both biliary and pancreatic duct. ${ }^{46}$

\section{Anomalous Pancreatobiliary Ductal Union (APBDU)}

An elongated pancreatobiliary junction (common channel $>1.5 \mathrm{~cm}$ ) has also been associated with RAP. Pancreatitis in APBDU probably occurs due to bile reflux into the pancreatic duct. Treatment with sphincterotomy may prevent future episodes of AP but benefits are uncertain. Cholecystectomy is recommended in these patients owing to an increased risk of gallbladder cancer and frequent association with choledochal cyst. ${ }^{44}$

\section{Pancreas Divisum}

Pancreas divisum is the most common congenital anomaly of the pancreas and is seen in 5-14\% of the general population. It results from failure of the dorsal and ventral pancreatic ducts to fuse during gestation. ${ }^{43}$ The majority of patients with pancreas divisum are asymptomatic. Instead, only those with this anomaly and increased risk of pancreatitis due to coexisting disorder such as from genetic mutations (cystic fibrosis transmembrane conductance regulator), environmental exposures (alcohol, smoking), or associated morphologic abnormality such as a santorinicele, develop RAP. ${ }^{44}$ In symptomatic patients with RAP, after a comprehensive evaluation, to rule out other causes of pancreatitis, endotherapy may be offered. ERCP with minor papilla sphincterotomy is the preferred endoscopic intervention to prevent recurrent attacks of $\mathrm{AP}^{47}$ After sphincterotomy, placement of a shortterm dorsal PD stent is preferred to avoid the risk of pancre- atitis and cicatricial strictures. The risk of post ERCP pancreatitis is greater in patients of pancreatic divisum without $\mathrm{CP}^{48}$ Evidence from most retrospective series report resolution of symptoms in $60-100 \%$ of patients post endotherapy. ${ }^{45}$ A meta-analysis of 23 studies reported a pooled success rate of $67.5 \%$; by subgroup, pooled success rates were $76 \%$ for RAP, $52.4 \%$ for $\mathrm{CP}$, and $48 \%$ for pancreatic-type pain. These results show that endotherapy is most effective in patients of pancreatic divisum presenting with RAP. $^{49} \mathrm{~A}$ case series of seven patients from north India with RAP and pancreatic divisum reported long term symptomatic improvement after endoscopic papillotomy of minor papilla. ${ }^{50}$

Mariani et al analyzed 33 patients of RAP with pancreatic divisum with follow-up of up to 5 years and reported similar CP findings on EUS in patients post endotherapy and the observation group (63.2\% and $57.1 \%$ ). These results suggest a tendency to progress to $\mathrm{CP}$ persists even after successful endotherapy likely due to underlying genetic mutations in these patients. ${ }^{51}$

\section{Sphincter of Oddi (SOD) Dysfunction}

Type 1 and Type 2 SOD are relevant in the etiology of RAP. Type 1 SOD is associated with mild dilation of either CBD or PD or both due to persistent obstruction to bile or pancreatic outflow and diagnosed based on clinical findings. Type 2 SOD is associated with sphincter motor dysfunction without any ductal dilation and diagnosis requires secretin test or sphincter of Oddi manometry. ${ }^{52}$ Involvement of both biliary and pancreatic sphincters is the most common form of involvement in SOD. ${ }^{45}$ Endoscopic sphincterotomy is the first line of management in type 1 SOD and type 2 SOD with documented sphincter dysfunction. Biliary sphincterotomy can be attempted first with reported clinical improvement in 83$100 \%$ of patients with type 1 SOD and up to $80 \%$ in type 2 SOD with documented sphincter dysfunction. Endoscopic pancreatic sphincterotomy can be attempted if symptoms recur. A dual sphincterotomy is also an option but an RCT comparing biliary and dual sphincterotomy in patients with RAP and pancreatic SOD reported similar incidence in two groups with higher rates of RAP in the dual therapy group during the first 12 months period. ${ }^{53}$ Short-term stenting or overnight nasopancreatic drainage is recommended to decrease the chances of pancreatitis following pancreatic sphincterotomy. ${ }^{54}$ Re-stenosis requiring re-intervention is reported in $41.7 \%$ of patients in a retrospective analysis of 369 patients following pancreatic sphincterotomy for RAP or Pancreatic SOD. ${ }^{55}$

\section{Autoimmune Pancreatitis}

Autoimmune pancreatitis (AIP) is a rare cause of RAP (more common with type 2 than type 1 ). EUS can aid in its diagnosis via fine-needle biopsy.

\section{Idiopathic Recurrent Acute Pancreatitis}

No identifiable cause is found even after thorough laboratory evaluation, genetic tests, or imaging studies in $10-30 \%$ of patients with recurrent pancreatitis. ${ }^{42}$ The diagnostic yield of EUS is $68-80 \%$ in patients with idiopathic pancreatitis with 

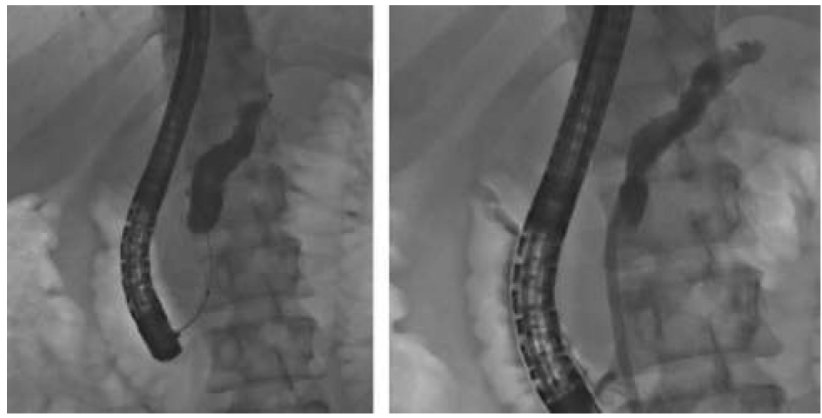

Fig. 2 (A) ERCP: Stricture in the head of the pancreas with an upstream dilated pancreatic duct. (B) Placement of a $10 \mathrm{Fr}$ plastic stent after dilatation of stricture with a balloon.

gall bladder in situ and a little lower in patients with the previous cholecystectomy. ${ }^{56}$ Occult microlithiasis has been reported as the cause of Idiopathic RAP in up to $73 \%$ of cases. ${ }^{45}$ EUS should be performed after the first episode of idiopathic pancreatitis, particularly if the patient has not undergone cholecystectomy or is $>40$ years of age. $43,44,57$

\section{Endotherapy in Chronic Pancreatitis}

\section{Pancreatic Ductal Endotherapy}

PD strictures and/or stones in patients with chronic pancreatitis can result in recurrent abdominal pain by causing a ductal obstruction. Endoscopic therapy is usually considered as first-line therapy for interventional management of PD stricture and includes pancreatic sphincterotomy, followed by dilatation of stricture, extraction of pancreatic duct stones, and PD stent placement (-Fig. 2). Multiple options are available for dilatation of stricture, which includes balloon or Bougie dilators and Soehendra stent retriever or cystotome if the dilator cannot traverse the stricture

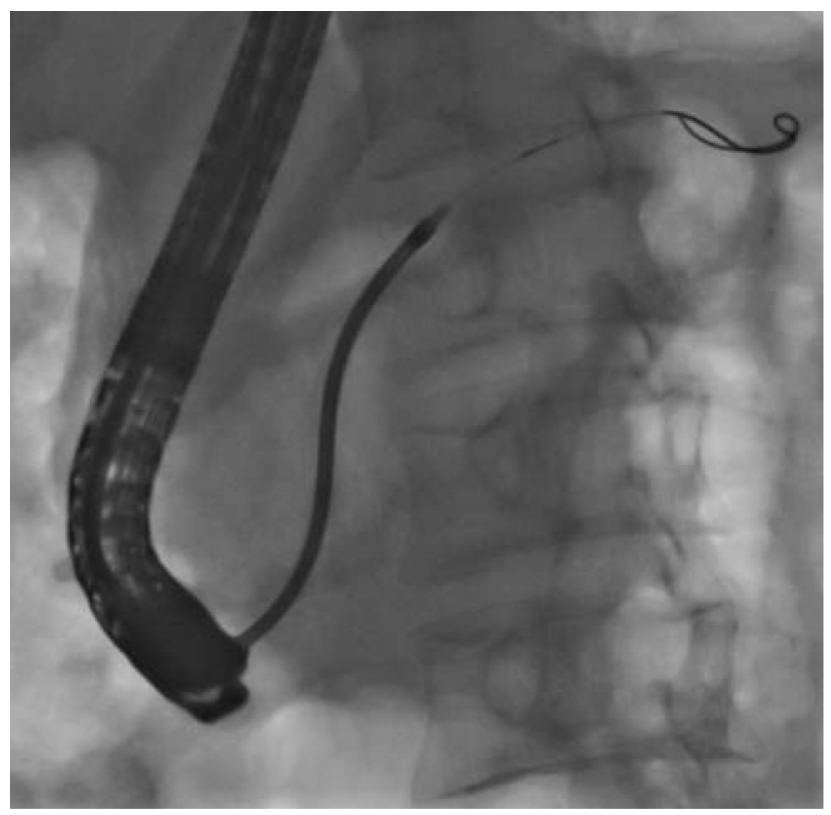

Fig. 3 Dilatation of the pancreatic duct stricture using the Soehendra stent retriever.
(-Fig. 3) ${ }^{58,59}$ Plastic stents can be exchanged upon the recurrence of symptoms or on a scheduled basis. Single 10-Fr plastic stent across the dominant stricture is preferred to avoid multiple hospital admissions for pain as smaller stents are prone to occlusion. Multiple small studies have evaluated fully covered self-expandable metal stents (FCSEMS) for managing pancreatic duct strictures (-Fig. 4). A recent meta-analysis of ten studies with 163 patients reported a stricture resolution rate of $93 \%$ (95\%CI 84-99\%) with an overall rate of adverse events being $34.9 \%$ in patients with FCSEMS compared with a complication rate of $7.85 \%$ in patients with plastic stents. ${ }^{60}$ Another meta-analysis comparing FCSEMS and multiple plastic stents in refractory PD stricture reported similar improvement in pain after stenting, risk of recurrence of pain after stent removal, and stricture resolution with a significantly higher risk of adverse events with FCSEMS. ${ }^{61}$ Lack of long-term data and clinical experience of significantly high adverse events including development of new strictures warrants further evaluation and improvement in stent design before FCSEMS can be routinely recommended for pancreatic duct strictures. ${ }^{58}$

The number and location of ductal stricture are the major factors determining the success of pancreatic endotherapy. A single stricture in the head of the pancreas is an ideal candidate for pancreatic endotherapy compared with a patient with stricture in the tail of the pancreas or multiple ductal strictures. ERCP has a technical failure rate of 3-10\% and the common reasons include failure of cannulation of the main pancreatic duct, tight non-negotiable strictures, pancreatic stones, or altered gastroduodenal anatomy (Whipple's procedure, Billroth II, Roux-en-Y gastric bypass). In such patients, EUS-guided PD drainage has evolved as a minimally invasive alternative to surgery. ${ }^{58}$ EUS can facilitate a
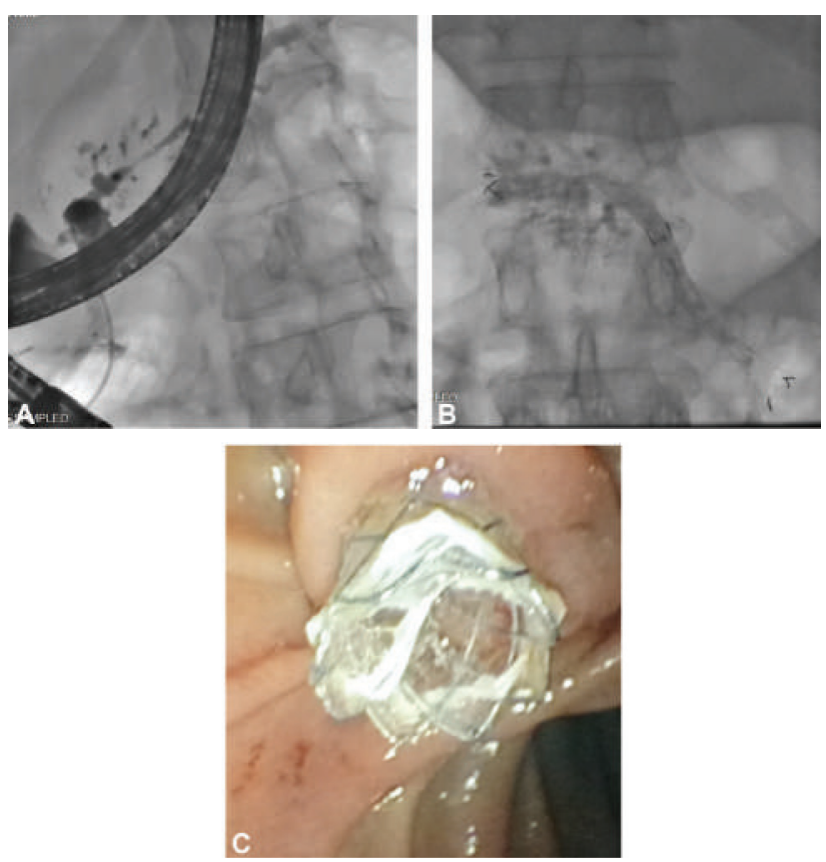

Fig. 4 (A) ERCP: Tight pancreatic duct stricture. (B) Placement of fully covered SEMS across the ductal stricture. (C) Fully covered SEMS across the papilla. 

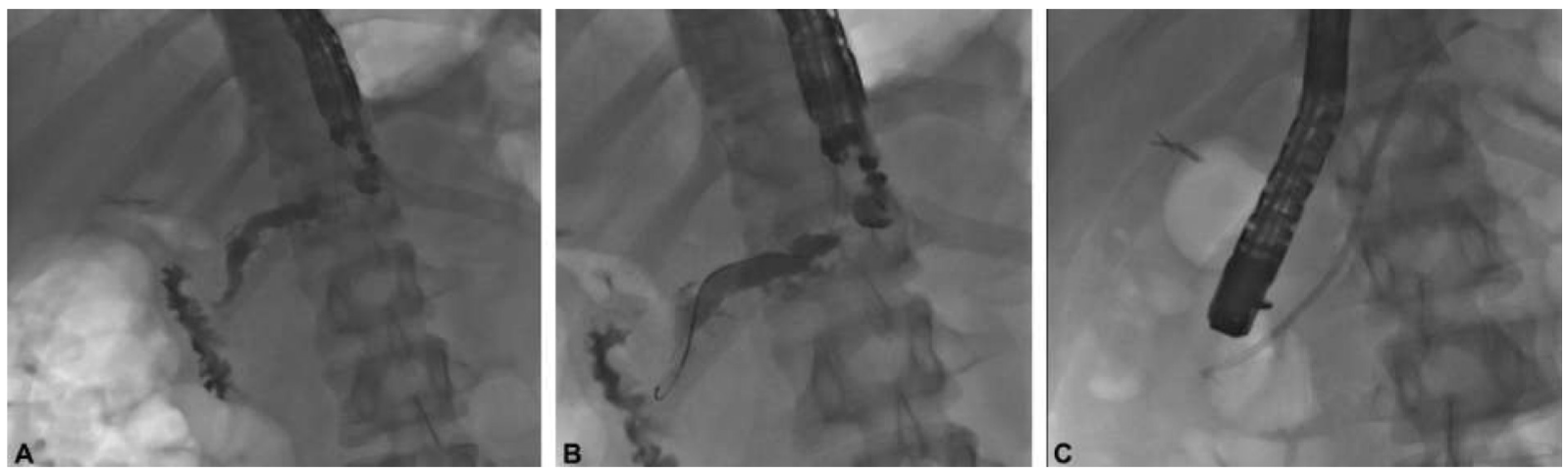

Fig. 5 (A) EUS-guided rendezvous: pancreatogram obtained after puncturing of the pancreatic duct. (B) Guidewire being negotiated across the stricture in the pancreatic duct. (C) A stent placed after exchanging the echoendoscope with a duodenoscope.

rendezvous procedure (-Fig. 5 ) or provide transgastric or transduodenal pancreatic duct stent placement. ${ }^{58}$

Pancreatic sphincterotomy and stone retrieval can rarely be achieved using standard biliary stone removal techniques, as the pancreatic duct stones are usually calcified and hard. Moreover, they are either usually impacted within side branches or are upstream to coexistent PD strictures making endoscopic removal difficult. Extracorporeal shockwave lithotripsy (ESWL) can be used to fragment stones prior to endoscopic removal and is usually recommended for clearance of radiopaque obstructive main pancreatic stones larger than $5 \mathrm{~mm}$ located in the head/body of the pancreas. ${ }^{62}$ Factors predicting failure of ESWL include stone in the tail, extensive calculi throughout the pancreas, PD stricture, and early post-ESWL ( $<2$ days) ERCP attempt. The overall complication rate with ESWL is around 6\% and the most common complication is pancreatitis. ${ }^{63}$ EHL (Electrohydraulic lithotripsy) and LL (Laser lithotripsy) under pancreatoscopic guidance has also been used to fragment and remove obstructing stones as rescue therapy or as first-line therapy when ESWL is not available. ${ }^{64}$ A recent meta-analysis on the efficacy of peroral pancreatoscopy (POP) for pancreatic duct stones using these two techniques (Ten of included studies reported outcomes on POP using EHL and 8 studies reported outcomes on POP using LL) demonstrated technical and clinical success rates of $76.4 \%$ and $76.8 \%$ respectively with POP. $^{65}$ Therefore limited data suggest it to be viable and effective option for management of pancreatic duct calculi in chronic pancreatitis. ${ }^{64}$

Endotherapy is associated with higher clinical and technical success rates in patients with a single stricture, stone less than $1 \mathrm{~cm}$ in size, 3 or fewer stones in number, and disease limited to the head or proximal body of the pancreas. ${ }^{58}$ Recent ESGE guidelines suggest endoscopic therapy and/or ESWL as the first-line therapy for painful uncomplicated chronic pancreatitis with an obstructed main PD in the head or body of the pancreas. ${ }^{62}$

\section{Pseudocyst}

The endoscopic approach for the management of pseudocyst associated with chronic pancreatitis is similar to that for acute pseudocyst discussed in the previous sections. How- ever underlying ductal abnormalities may lead to recurrences if left untreated and downstream pancreatic ductal obstruction from stones or fibrotic strictures should be endoscopically managed to prevent recurrences. Pancreatic pseudocysts occurring at atypical locations such as in the kidneys, liver, and spleen can also be treated endoscopically. ${ }^{66-68}$

\section{Celiac Plexus Block}

EUS guided Celiac Plexus Block (CPB) involves the injection of an anesthetic with a steroid into the celiac plexus region or directly into the celiac ganglia. Higher clinical success rates were reported in a randomized study from India after EUS$\mathrm{CPB}$ as compared with percutaneous $\mathrm{CPB} .{ }^{69}$ Despite being considered safe, the long-term efficacy and duration of pain relief following $\mathrm{CPB}$ are limited. Also, central sensitization in $\mathrm{CP}$ patients renders $\mathrm{CPB}$ less effective for pain control. ${ }^{8}$

\section{Biliary Strictures}

Recurrent inflammation and fibrotic process within the pancreatic head can encase the distal bile duct and result in the formation of a distal biliary stricture which can lead to cholangitis and secondary biliary cirrhosis. Pancreatic calcification in $\mathrm{CP}$ renders them more refractory to endoscopic therapy as compared with other benign biliary strictures. ${ }^{70}$ Malignancy should always be excluded in this setting before planning any therapy. Persistent asymptomatic elevation of alkaline phosphatase or jaundice for more than 1 month should be taken as an indication of endoscopy therapy as edema or associated PFC's usually resolved in this time frame and waiting any longer will increase chances of secondary biliary cirrhosis which is relatively frequent. ${ }^{62}$

Balloon dilation and endoscopic guided insertion of multiple plastic stents or a fully covered self-expandable metal stent (SEMS) across the biliary stricture is the first line of treatment. An RCT in CP patients showed that six $10 \mathrm{Fr}$ plastic stents placed sequentially in 2 sessions every 3 months ( 3 stents at a time) and a fully covered $10 \mathrm{~mm}$ SEMS provided similar success rates ( $88.0 \%$ versus $90.9 \%$, respectively) at 2 years after stent removal (Stent duration 6 months) with similar treatment-related morbidity. ${ }^{71}$ Plastic biliary stents are usually placed in a sequential manner in increasing 
numbers over 1 year, with stent exchanges every 3-4 months. The scheduled duration of a metallic stent is usually kept as 6-12 months. A recent international multicenter study showed the placement of a single FCSEMS for 10-12 months results in good long-term results in patients with benign biliary strictures and with an acceptable safety profile even 5 years after stent placement. ${ }^{72}$ Available data supports the use of fully covered SEMS as a first-line option over plastic stents. Failure of stricture to resolve after 12 months or three endoscopic procedures is considered an indication for surgery. The presence of associated inflammatory mass is an indication for early surgical referral. ${ }^{73}$

\section{Pancreatic Duct Leaks}

PD leaks may occur as a complication of pancreatitis (acute or chronic), trauma as well as after pancreatic surgery. ${ }^{74}$ Indwelling surgical drains can control most PD leaks following pancreatic surgery. Many of these leaks will close over time, and endoscopic therapy is generally reserved for refractory or persistent PD leaks. ${ }^{75}$

In the setting of a large PFC, transmural drainage may be undertaken, with or without concomitant transpapillary therapy. ${ }^{76}$ In the absence of any PFC, transpapillary PD stent placement to promote internal drainage is usually sufficient to heal the duct disruption. ${ }^{77}$

\section{Endotherapy in Pancreatic Cancer}

\section{Obstructive Jaundice}

ERCP-guided biliary drainage (BD) is considered the first line modality for palliation of malignant biliary obstruction. In addition to failed biliary cannulation, duodenal infiltration of pancreatic tumor can be encountered leading to failure of ERCP guided BD. ${ }^{78}$ EUS-guided biliary drainage (EUS-BD) is now being utilized in the management of biliary obstruction with failed ERCP as an alternative to percutaneous transhepatic biliary drainage (PTBD). In a systematic review, EUS$\mathrm{BD}$ had better clinical success (odds ratio, $0.45 ; p=0.02$ ), similar technical success (odds ratio, 1.78; $p=0.25$ ) and lesser adverse events (odds ratio, 0.23; $p<0.0001$ ) as compared with PTBD. ${ }^{79}$ However, it is still unclear whether EUSBD can adversely affect clinical outcomes, either oncologically or surgically in patients with resectable or borderline resectable cancers, and therefore the decision to proceed with EUS BD in such cases requires consultation among a multidisciplinary team. ${ }^{80}$

\section{Gastric Outlet Obstruction}

Gastric outlet obstruction (GOO) due to duodenal invasion by a pancreatic tumor can be seen in 15 to $20 \%$ of patients. Endoscopic placement of an uncovered SEMS is an effective method of palliation, with a more rapid return of oral intake but with an increased risk of occlusion and need for reintervention as compared with bypass surgery. EUS guided gastroenterostomy (GE) whereby the stomach is anastomosed to the duodenum or jejunum using a LAMS is a newer nonsurgical intervention for the palliation of GOO. A retrospective cohort study from single-center analyzed patients with GOO who underwent EUS-GE or open gastrojejunostomy (OGJ) and reported reduced hospital costs, shorter hospital stay and quicker institution to the resumption of oral intake and chemotherapy with EUS-GE. ${ }^{81}$

\section{Endoscopic-guided Radiofrequency Ablation}

Endoscopic radiofrequency ablation (RFA) is a minimally invasive approach used for tumor ablation. Radiofrequency-induced hyperthermia causes coagulative necrosis of tumor tissue and a recent meta-analysis on the use of RFA for treatment of locally advanced unresectable pancreatic adenocarcinoma and other pancreatic tumors like neuroendocrine tumors has shown EUS-RFA to have high technical (100\%) and clinical (91.5\%) success rates. ${ }^{82}$ Re-canalization of biliary or pancreatic duct obstruction by unresectable tumors using RFA with subsequent stent placement has been successfully achieved with reported prolonged stent patency. ${ }^{83}$

\section{EUS-Guided Fine-Needle Tattooing}

Preoperative EUS-guided fine-needle tattooing (EUS-FNT) helps in the accurate localization of pancreatic tumors during surgery and is being increasingly used for patients with lesions in the distal pancreas. A retrospective cohort study comparing EUS-FNT followed by laparoscopic distal pancreatectomy (LDP) and LDP alone reported that preoperative EUS-FNT was safe and feasible, with shorter operative time and led to $\mathrm{R} 0$ resection in all patients without any complications. ${ }^{84}$

\section{EUS-guided Fiducial Placement}

EUS guided fiducial placement is safe and effective in patients with borderline resectable, locally advanced, and metastatic pancreatic cancer patients who have been undergoing radiation therapy as it improves the accuracy of target delineation and reduced radiation exposure. Recent international guidelines on the management of pancreatic adenocarcinoma (NCCN version 1.2020) have recommended placement of $1-5$ (preferably $\geq 3$ ) gold fiducial markers preferentially by EUS in patients with localized pancreatic cancer (resectable, borderline, and locally advanced) for targeted radiotherapy. ${ }^{85}$ New preloaded needles appear to reduce the procedure time along with the reduced risk of needle stick injuries compared to the traditional back-loaded needles. $^{86}$

\section{Role of Endotherapy in Management of Pancreatic Cystic Lesions}

Pancreatic protocol CT and MRCP along with clinical context are usually sufficient for accurate diagnosis of pancreatic cystic lesions. EUS can be utilized as third line tool in remaining cases. ${ }^{87}$ EUS FNA is not routinely recommended for pancreatic cystic lesions in view of low diagnostic yield and risk of tumor seeding which despite being rare is a 
matter of serious concern. Therefore, EUS FNA should be done only when it could change management. ${ }^{88}$ Analysis of molecular DNA markers and use of micro forceps biopsy devices for sampling are recent methods that have shown great promise in improving preoperative diagnostic yield of EUS FNA. $^{89}$

Molecular DNA markers specific to the type of pancreatic cysts are evaluated which increases the diagnostic yield of the aspirated sample. The microforceps or through the needle biopsy device pass through standard 19 G EUS FNA needle to obtain targeted tissue samples under direct EUS vision. This method is feasible for even small pancreatic cysts irrespective of location. A metaanalysis of 8 studies (mostly restrospective and small sample size) comparing both these techniques with surgical pathology specimen as reference standard has shown that microforceps biopsies led to a high diagnostic yield (73\%) and a high rate of correctly identifying cyst subtypes (70.7\%). ${ }^{90}$

EUS guided pancreatic cystic ablation can be performed with alcohol-free chemoablation or radiofrequency. Typical indications for ablative therapy are not well defined but it can be considered for patients with branch duct IPMN and mucinous cystadenoma $(2-6 \mathrm{~cm})$ who are not candidates for surgery with good life expectancy or in patients refusing surgery. ${ }^{91}$ Multi-agent chemoablation regimens containing both paclitaxel and gemcitabine have shown encouraging results with an overall complete response rate of $64 \%$ at 12 months. ${ }^{92}$ A large prospective multicenter study analyzed outcomes of EUS-RFA in 17 patients of pancreatic cystic neoplasms (mean size $28 \mathrm{~mm}$, range $9-60 \mathrm{~mm}$ ). They reported a significant response rate of $71 \%$ (11 complete disappearances and 1 showing $>50 \%$ decrease in diameter) with all 12 mural nodules showing complete resolution. ${ }^{93}$

\section{Role of Endotherapy in Management of pNET}

Pancreatic NETs are rare, accounting $<2 \%$ of all pancreatic tumors, and are usually diagnosed incidentally. EUS guided ablation therapies are promising options for nonfunctioning NETs and insulinomas measuring $<2 \mathrm{~cm} .{ }^{93,94}$ Ablation can be achieved with alcohol or RFA. In the largest case series of 11 patients with 14 tumors ( 4 insulinomas and 10 nonfunctional tumors) by Park et al, ${ }^{95} 7 / 13$ patients had a complete response after 1 session and 2 patients with insulinomas became asymptomatic with alcohol ablation. The risk of pancreatitis can be minimized by avoiding excess ethanol injection and keeping the needle in tumor tissue. A prospective multicenter study evaluated EUS RFA in 14 NETs and reported a complete resolution rate of $86 \%$ at 1 year with delayed response in 3 patients possible due to stimulation of immune response by release of antigens from necrotic tissue. ${ }^{93}$ Adequate prophylaxis (antibiotics and rectal NSAIDS) decreases post-procedure complication rates. RFA provides more controlled ablation as compared with alcohol and is therefore safer. However, longterm outcomes are still pending and also surveillance protocols after ablation are not well defined. ${ }^{96}$

\section{Conclusions}

Advancements in interventional techniques have put endoscopy at the forefront of the management of pancreatitis and its complications. The advent of interventional EUS has further expanded the scope and indications of pancreatic endotherapy along with considerable reductions in adverse events. The further development and refinement of EUS dedicated stents will expand the indications of pancreatic endotherapy.

Conflict of Interest

None declared.

\section{References}

1 Buonocore MR, Germani U, Castellani D, et al. Timing of endoscopic therapy for acute bilio-pancreatic diseases: a practical overview. Ann Gastroenterol 2021;34(02):125-129. Doi: 10.20524/aog.2021.0580

2 Schepers NJ, Hallensleben NDL, Besselink MG, et al; Dutch Pancreatitis Study Group. Urgent endoscopic retrograde cholangiopancreatography with sphincterotomy versus conservative treatment in predicted severe acute gallstone pancreatitis (APEC): a multicentre randomised controlled trial. Lancet 2020; 396(10245):167-176

3 Arvanitakis M, Ockenga J, Bezmarevic M, et al. ESPEN guideline on clinical nutrition in acute and chronic pancreatitis. Clin Nutr 2020;39(03):612-631. Doi: 10.1016/j.clnu.2020.01.004

4 Sharma V, Rana SS, Sharma R, Chaudhary V, Gupta R, Bhasin DK. Naso-jejunal fluid resuscitation in predicted severe acute pancreatitis: Randomized comparative study with intravenous Ringer's lactate. J Gastroenterol Hepatol 2016;31(01):265-269. Doi: 10.1111/jgh.13047

5 Rana SS, Chaudhary V, Sharma R, Sharma V, Chhabra P, Bhasin DK. Impact of nasojejunal feeding on outcome of patients with walled off pancreatic necrosis (WOPN) presenting with pain: a pilot study. J Gastrointest Surg 2015;19(09):1621-1624. Doi: 10.1007/ s11605-015-2843-y

6 Braha J, Tenner S. Fluid collections and pseudocysts as a complication of acute pancreatitis. Gastrointest Endosc Clin N Am 2018; 28(02):123-130

7 van Santvoort HC, Bakker OJ, Bollen TL, et al.Dutch Pancreatitis Study Group. A conservative and minimally invasive approach to necrotizing pancreatitis improves outcome. Gastroenterology 2011;141:1254-1263

8 Gurakar M, Faghih M, Singh VK. Endoscopic intervention in pancreatitis: perspectives from a gastroenterologist. Abdom Radiol (NY) 2020;45(05):1308-1315. Doi: 10.1007/s00261-01902314-7

9 Trikudanathan G, Tawfik P, Amateau SK, et al. Early ( $<4$ weeks) versus standard ( $\geq 4$ weeks) endoscopically centered step-up interventions for necrotizing pancreatitis. Am J Gastroenterol 2018;113(10):1550-1558. Doi: 10.1038/s41395-018-0232-3

10 Rana SS, Verma S, Kang M, Gorsi U, Sharma R, Gupta R. Comparison of endoscopic versus percutaneous drainage of symptomatic pancreatic necrosis in the early $(<4$ weeks) phase of illness. Endosc Ultrasound 2020;9(06):402-409. Doi: 10.4103/eus. eus_65_20

11 Rana SS, Sharma R, Kishore K, Dhalaria L, Gupta R. Safety and efficacy of early ( $<4$ weeks of illness) endoscopic transmural drainage of post-acute pancreatic necrosis predominantly located in the body of the pancreas. J Gastrointest Surg 2021;25(09): 2328-2335. Doi: 10.1007/s11605-021-04945-y 
12 Mouli VP, Sreenivas V, Garg PK. Efficacy of conservative treatment, without necrosectomy, for infected pancreatic necrosis: a systematic review and meta-analysis. Gastroenterology 2013;144 (02):333-340.e2

13 Takahashi N, Papachristou GI, Schmit GD, et al. CT findings of walled-off pancreatic necrosis (WOPN): differentiation from pseudocyst and prediction of outcome after endoscopic therapy. Eur Radiol 2008;18(11):2522-2529

14 Rana SS. An overview of walled-off pancreatic necrosis for clinicians. Expert Rev Gastroenterol Hepatol 2019;13(04): 331-343

15 Rana SS, Sharma RK, Gupta P, Gupta R. Natural course of asymptomatic walled off pancreatic necrosis. Dig Liver Dis 2019;51(05): 730-734

16 Samuelson AL, Shah RJ. Endoscopic management of pancreatic pseudocysts. Gastroenterol Clin North Am 2012;41(01):47-62

17 Varadarajulu S, Rana SS, Bhasin DK. Endoscopic therapy for pancreatic duct leaks and disruptions. Gastrointest Endosc Clin N Am 2013;23(04):863-892

18 Hookey LC, Debroux S, Delhaye M, Arvanitakis M, Le Moine O, Devière J. Endoscopic drainage of pancreatic-fluid collections in 116 patients: a comparison of etiologies, drainage techniques, and outcomes. Gastrointest Endosc 2006;63(04):635-643

19 Yang D, Amin S, Gonzalez S, et al. Transpapillary drainage has no added benefit on treatment outcomes in patients undergoing EUS-guided transmural drainage of pancreatic pseudocysts: a large multicenter study. Gastrointest Endosc 2016;83(04): 720-729

20 Rana SS, Sharma V, Sharma R. Endoscopic transmural drainage versus combined transmural and transpapillary drainage in pseudocysts. Gastrointest Endosc 2016;84(03):548-549. Doi: 10.1016/j.gie.2016.03.1490

21 Bhasin DK, Rana SS, Nanda M, et al. Comparative evaluation of transpapillary drainage with nasopancreatic drain and stent in patients with large pseudocysts located near tail of pancreas. J Gastrointest Surg 2011;15(05):772-776

22 Telford JJ, Farrell JJ, Saltzman JR, et al. Pancreatic stent placement for duct disruption. Gastrointest Endosc 2002;56(01):18-24

23 Binmoeller KF, Nett A. The evolution of endoscopic cystgastrostomy. Gastrointest Endosc Clin N Am 2018;28(02):143-156

24 Park DH, Lee SS, Moon SH, et al. Endoscopic ultrasound-guided versus conventional transmural drainage for pancreatic pseudocysts: a prospective randomized trial. Endoscopy 2009;41(10): 842-848

25 Varadarajulu S, Christein JD, Tamhane A, Drelichman ER, Wilcox CM. Prospective randomized trial comparing EUS and EGD for transmural drainage of pancreatic pseudocysts (with videos). Gastrointest Endosc 2008;68(06):1102-1111

26 Guzmán-Calderón E, Chacaltana A, Díaz R, Li B, Martinez-Moreno B, Aparicio JR. Head-to-head comparison between endoscopic ultrasound guided lumen apposing metal stent and plastic stents for the treatment of pancreatic fluid collections: a systematic review and meta-analysis. [published online ahead of print, 2021 Jun 9]J Hepatobiliary Pancreat Sci 2021. Doi: 10.1002/jhbp. 1008

27 Chen YI, Khashab MA, Adam V, et al. Plastic stents are more costeffective than lumen-apposing metal stents in management of pancreatic pseudocysts. Endosc Int Open 2018;6(07):E780-E788. Doi: 10.1055/a-0611-5082

28 Shah R, Basha J, Rana S, et al. Endoscopic management of pancreatic fluid collections: Guidelines of Society of Gastrointestinal Endoscopy of India and Indian EUS Club. J Digest Endosc 2021;12:3-10

29 Alali A, Mosko J, May G, Teshima C. Endoscopic ultrasound-guided management of pancreatic fluid collections: update and review of the literature. Clin Endosc 2017;50(02):117-125

30 Hollemans RA, Bakker OJ, Boermeester MA, et al; Dutch Pancreatitis Study Group. Superiority of step-up approach vs open necrosectomy in long-term follow-up of patients with necrotizing pancreatitis. Gastroenterology 2019;156(04):1016-1026

31 Bakker OJ, van Santvoort HC, van Brunschot S, et al; Dutch Pancreatitis Study Group. Endoscopic transgastric vs surgical necrosectomy for infected necrotizing pancreatitis: a randomized trial. JAMA 2012;307(10):1053-1061

32 van Brunschot S, van Grinsven J, van Santvoort HC, et al; Dutch Pancreatitis Study Group. Endoscopic or surgical step-up approach for infected necrotising pancreatitis: a multicentre randomised trial. Lancet 2018;391(10115):51-58

33 Bang JY, Arnoletti JP, Holt BA, et al. An endoscopic transluminal approach, compared with minimally invasive surgery, reduces complications and costs for patients with necrotizing pancreatitis. Gastroenterology 2019;156(04):1027-1040.e3

34 Chen YI, Yang J, Friedland S, et al. Lumen apposing metal stents are superior to plastic stents in pancreatic walled-off necrosis: a large international multicenter study. Endosc Int Open 2019;7(03): E347-E354. Doi: 10.1055/a-0828-7630

35 Rana SS, Sharma R, Dhalaria L, Gupta R. Efficacy and safety of plastic versus lumen-apposing metal stents for transmural drainage of walled-off necrosis: a retrospective single-center study. Ann Gastroenterol 2020;33(04):426-432. Doi: 10.20524/ aog.2020.0499

36 Bang JY, Navaneethan U, Hasan MK, Sutton B, Hawes R, Varadarajulu $\mathrm{S}$. Non-superiority of lumen-apposing metal stents over plastic stents for drainage of walled-off necrosis in a randomised trial. Gut 2019;68(07):1200-1209

37 Rana SS, Sharma V, Sharma R, Gupta R, Bhasin DK. Endoscopic ultrasound guided transmural drainage of walled off pancreatic necrosis using a "step - up" approach: a single centre experience. Pancreatology 2017;17(02):203-208

38 Jagielski M, Jackowski M. The role of endoscopic transpapillary stenting of the main pancreatic duct during the endoscopic treatment of pancreatic fluid collections. J Clin Med 2021;10 (04):761. Doi: $10.3390 / j \mathrm{~cm} 10040761$

39 Verma S, Rana SS. Disconnected pancreatic duct syndrome: updated review on clinical implications and management. Pancreatology 2020;20(06):1035-1044. Doi: 10.1016/j. pan.2020.07.402

40 Rana SS, Shah J, Sharma RK, Gupta R. Clinical and morphological consequences of permanent indwelling transmural plastic stents in disconnected pancreatic duct syndrome. Endosc Ultrasound 2020;9(02):130-137

41 Rana SS, Sharma R, Gupta R. Endoscopic treatment of refractory external pancreatic fistulae with disconnected pancreatic duct syndrome. Pancreatology 2019;19(04):608-613

42 Guo A, Poneros JM. The role of endotherapy in recurrent acute pancreatitis. Gastrointest Endosc Clin N Am 2018;28(04): 455-476

43 Jagannath S, Garg PK. Recurrent acute pancreatitis: current concepts in the diagnosis and management. Curr Treat Options Gastroenterol 2018;16(04):449-465. Doi: 10.1007/s11938-0180196-9

44 Zakko L, Gardner TB. Endoscopic management of recurrent acute pancreatitis. Clin Gastroenterol Hepatol 2019;17(11):2167-2170. Doi: 10.1016/j.cgh.2019.04.069

45 Testoni PA, Testoni S. ERCP-guided endoscopic therapy for recurrent acute pancreatitis in normal pancreas and chronic pancreatitis. J Pancreas 2020

46 Guda NM, Romagnuolo J, Freeman ML. Recurrent and relapsing pancreatitis. Curr Gastroenterol Rep 2011;13(02):140-149

47 Gutta A, Fogel E, Sherman S. Identification and management of pancreas divisum. Expert Rev Gastroenterol Hepatol 2019;13 (11):1089-1105. Doi: 10.1080/17474124.2019.1685871

48 Meng QQ Zhao SB, Wang ZJ, et al. Incidence and risk factors for post-ERCP pancreatitis in pancreas divisum patients without chronic pancreatitis. Scand J Gastroenterol 2020;55(06): 732-736. Doi: 10.1080/00365521.2020.1774922 
49 Michailidis L, Aslam B, Grigorian A, Mardini H. The efficacy of endoscopic therapy for pancreas divisum: a meta-analysis. Ann Gastroenterol 2017;30(05):550-558[PMID: 28845111]

50 Goyal O, Singh A, Goyal P. Long term outcome of endoscopic minor papillotomy in patients with symptomatic pancreas divisum: experience from northern India. Asian Journal of Research and Reports in Gastroenterology 2020;3:6-11

51 Mariani A, Di Leo M, Petrone MC, et al. Outcome of endotherapy for pancreas divisum in patients with acute recurrent pancreatitis. World J Gastroenterol 2014;20(46):17468-17475[PMID: 25516660]

52 Yaghoobi M, Romagnuolo J. Sphincter of Oddi dysfunction: updates from the recent literature. Curr Gastroenterol Rep 2015;17(08):31[PMID: 26143628]

53 Coté GA, Imperiale TF, Schmidt SE, et al. Similar efficacies of biliary, with or without pancreatic, sphincterotomy in treatment of idiopathic recurrent acute pancreatitis. Gastroenterology 2012;143(06):1502-1509.e1[PMID: 22982183]

54 Elton E, Howell DA, Parsons WG, Qaseem T, Hanson BL. Endoscopic pancreatic sphincterotomy: indications, outcome, and a safe stentless technique. Gastrointest Endosc 1998;47(03): 240-249. Doi: 10.1016/s0016-5107(98)70320-7

55 Dufault DL, Elmunzer BJ, Cotton PB, Williams A, Cote GA. Adverse events and reinterventions following pancreatic endoscopic sphincterotomy. Pancreas 2018;47(07):880-883[PMID: 29912853]

56 Coyle WJ, Pineau BC, Tarnasky PR, et al. Evaluation of unexplained acute and acute recurrent pancreatitis using endoscopic retrograde cholangiopancreatography, sphincter of Oddi manometry and endoscopic ultrasound. Endoscopy 2002;34(08): 617-623

57 Rana SS, Bhasin DK, Rao C, Singh K. Role of endoscopic ultrasound in idiopathic acute pancreatitis with negative ultrasound, computed tomography, and magnetic resonance cholangiopancreatography. Ann Gastroenterol 2012;25(02):133-137

58 Jearth V, Giri S, Sundaram S. Approach to management of pancreatic strictures: the gastroenterologist's perspective. Clin J Gastroenterol 2021;14(06):1587-1597. Doi: 10.1007/s12328-02101503-6

59 Rana SS, Shah J, Bush N, Sharma R, Dhalaria L, Gupta R. Endoscopic dilatation of tight difficult pancreatic duct strictures: Soehendra stent retriever or wire guided cystotome. Pancreatology 2021;21 (02):498-499

60 Li TT, Song SL, Xiao LN, Wang CH. Efficacy of fully covered selfexpandable metal stents for the management of pancreatic duct strictures in chronic pancreatitis: a systematic review and metaanalysis. J Gastroenterol Hepatol 2020;35(07):1099-1106

61 Sofi AA, Khan MA, Ahmad S, et al. Comparison of clinical outcomes of multiple plastic stents and covered metal stent in refractory pancreatic ductal strictures in chronic pancreatitis - a systematic review and meta-analysis. Pancreatology 2021;21(05):854-861

62 Dumonceau JM, Delhaye M, Tringali A, et al. Endoscopic treatment of chronic pancreatitis: European Society of Gastrointestinal Endoscopy (ESGE) Guideline - Updated August 2018. Endoscopy 2019;51(02):179-193

63 Sharzehi K. Management of pancreatic duct stones. Curr Gastroenterol Rep 2019;21(11):63

64 Beyna T, Neuhaus H, Gerges C. Endoscopic treatment of pancreatic duct stones under direct vision: revolution or resignation? Systematic review. Dig Endosc 2018;30(01):29-37

65 Saghir SM, Mashiana HS, Mohan BP, et al. Efficacy of pancreatoscopy for pancreatic duct stones: a systematic review and metaanalysis. World J Gastroenterol 2020;26(34):5207-5219. Doi: 10.3748/wjg.v26.i34.5207

66 Rana SS, Sharma R, Chhabra P, Sharma V, Gupta R, Bhasin DK. Endoscopic management of splenic pseudocysts associated with acute and chronic pancreatitis. Ann Gastroenterol 2016;29(03): 373-377
67 Bhasin DK, Rana SS, Nanda M, et al. Endoscopic management of pancreatic pseudocysts at atypical locations. Surg Endosc 2010; 24(05):1085-1091

68 Rana SS, Dawra S, Sharma R, Kang M, Gupta R. Clinical manifestations, imaging features, and endoscopic management of renal pseudocysts: a case series. Ann Gastroenterol 2020;33(03): 313-317

69 Santosh D, Lakhtakia S, Gupta R, et al. Clinical trial: a randomized trial comparing fluoroscopy guided percutaneous technique vs. endoscopic ultrasound guided technique of coeliac plexus block for treatment of pain in chronic pancreatitis. Aliment Pharmacol Ther 2009;29(09):979-984

70 Familiari P, Boškoski I, Bove V, Costamagna G. ERCP for biliary strictures associated with chronic pancreatitis. Gastrointest Endosc Clin N Am 2013;23(04):833-845

71 Haapamäki C, Kylänpää L, Udd M, et al. Randomized multicenter study of multiple plastic stents vs. covered self-expandable metallic stent in the treatment of biliary stricture in chronic pancreatitis. Endoscopy 2015;47(07):605-610

72 Lakhtakia S, Reddy N, Dolak W, et al; Benign Biliary Stenoses Working Group. Long-term outcomes after temporary placement of a self-expanding fully covered metal stent for benign biliary strictures secondary to chronic pancreatitis. Gastrointest Endosc 2020;91(02):361-369.e3. Doi: 10.1016/j.gie.2019.08.037

73 Regimbeau JM, Fuks D, Bartoli E, et al. A comparative study of surgery and endoscopy for the treatment of bile duct stricture in patients with chronic pancreatitis. Surg Endosc 2012;26(10): 2902-2908. Doi: 10.1007/s00464-012-2283-7

74 Bhasin DK, Rana SS, Rawal P. Endoscopic retrograde pancreatography in pancreatic trauma: need to break the mental barrier. J Gastroenterol Hepatol 2009;24(05):720-728

75 Rana SS, Bhasin DK, Nanda M, et al. Endoscopic transpapillary drainage for external fistulas developing after surgical or radiological pancreatic interventions. J Gastroenterol Hepatol 2010;25 (06):1087-1092

76 Bhasin DK, Rana SS. Combining transpapillary pancreatic duct stenting with endoscopic transmural drainage for pancreatic fluid collections: two heads are better than one!. J Gastroenterol Hepatol 2010;25(03):433-434

77 Bakker OJ, van Baal MC, van Santvoort HC, et al; Dutch Pancreatitis Study Group. Endoscopic transpapillary stenting or conservative treatment for pancreatic fistulas in necrotizing pancreatitis: multicenter series and literature review. Ann Surg 2011;253 (05):961-967

78 Nakai Y, Hamada T, Isayama H, Itoi T, Koike K. Endoscopic management of combined malignant biliary and gastric outlet obstruction. Dig Endosc 2017;29(01):16-25

79 Sharaiha RZ, Khan MA, Kamal F, et al. Efficacy and safety of EUSguided biliary drainage in comparison with percutaneous biliary drainage when ERCP fails: a systematic review and meta-analysis. Gastrointest Endosc 2017;85(05):904-914

80 Nakai Y, Takahara N, Mizuno S, Kogure H, Koike K. Current status of endoscopic ultrasound techniques for pancreatic neoplasms. Clin Endosc 2019;52(06):527-532. Doi: 10.5946/ ce.2019.025

81 Kouanda A, Binmoeller K, Hamerski C, Nett A, Bernabe J, Watson R. Endoscopic ultrasound-guided gastroenterostomy versus open surgical gastrojejunostomy: clinical outcomes and cost effectiveness analysis. Surg Endosc 2021;35(12):7058-7067. Doi: 10.1007/s00464-020-08221-z

82 Dhaliwal A, Kolli S, Dhindsa BS, et al. Efficacy of EUS-RFA in pancreatic tumors: is it ready for prime time? A systematic review and meta-analysis. Endosc Int Open 2020;8(10):E1243-E1251. Doi: $10.1055 / \mathrm{a}-1221-5012$

83 Wang J, Zhao L, Zhou C, et al. Percutaneous intraductal radiofrequency ablation combined with biliary stent placement for nonresectable malignant biliary obstruction improves stent 
patency but not survival. Medicine (Baltimore) 2016;95(15): e3329. Doi: 10.1097/MD.0000000000003329

84 Lennon AM, Newman N, Makary MA, et al. EUS-guided tattooing before laparoscopic distal pancreatic resection (with video). Gastrointest Endosc 2010;72(05):1089-1094

85 Tempero MA, Malafa MP, Al-Hawary M, et al. Pancreatic adenocarcinoma, version 1.2020. Plymouth Meeting: National Comprehensive Cancer Network 2019

86 Machicado JD, Obuch JC, Goodman KA, et al. Endoscopic ultrasound placement of preloaded fiducial markers shortens procedure time compared to back-loaded markers. Clin Gastroenterol Hepatol 2019;17(13):2749-2758.e2

87 Lévy P, Rebours V. The role of endoscopic ultrasound in the diagnosis of cystic lesions of the pancreas. Visc Med 2018;34 (03):192-196. Doi: 10.1159/000489242

88 European Study Group on Cystic Tumours of the Pancreas. European evidence-based guidelines on pancreatic cystic neoplasms. Gut 2018;67(05):789-804

$89 \mathrm{Koo} \mathrm{CS}$, Ho KY. The role of EUS-FNA in the evaluation of pancreatic cystic lesions. Endosc Ultrasound 2020;9(02):71-75. Doi: 10.4103/eus.eus_4_20

90 Faias S, Pereira L, Luís Â, Chaves P, Cravo M. Genetic testing vs microforceps biopsy in pancreatic cysts: systematic review and meta-analysis. World J Gastroenterol 2019;25(26): 3450-3467

91 Bispo M, Caldeira A, Leite S, et al. Endoscopic ultrasoundguided ablation of focal pancreatic lesions: the GRUPUGE perspective. GE Port J Gastroenterol 2020;27(06):410-416. Doi: 10.1159/000507895

92 Moyer MT, Sharzehi S, Mathew A, et al. The safety and efficacy of an alcohol-free pancreatic cyst ablation protocol. Gastroenterology 2017;153(05):1295-1303

93 Barthet M, Giovannini M, Lesavre N, et al. Endoscopic ultrasoundguided radiofrequency ablation for pancreatic neuroendocrine tumors and pancreatic cystic neoplasms: a prospective multicenter study. Endoscopy 2019;51(09):836-842

94 Lakhtakia S, Ramchandani M, Galasso D, et al. EUS-guided radiofrequency ablation for management of pancreatic insulinoma by using a novel needle electrode (with videos). Gastrointest Endosc 2016;83(01):234-239

95 Park DH, Choi JH, Oh D, et al. Endoscopic ultrasonographyguided ethanol ablation for small pancreatic neuroendocrine tumors: results of a pilot study. Clin Endosc 2015;48(02): $158-164$

96 So H, Oh D, Seo D. Recent developments in endoscopic ultrasoundguided ablation treatment. Int J Gastrointest Interv 2020;9:135-141 